\title{
The Role of Radiotherapy in the Treatment and Diagnosis of Pseudomalignant Vertebral Haemangiomatosis: A Case Report
}

\author{
Colby Eisenbach ${ }^{*}$, Chase Hansen and Carlos Torres
}

TTUHSC School of Medicine, USA

*Corresponding author: Colby Eisenbach, Medical Student, TTUHSC School of Medicine, USA, Tel: + 432-425-1855; E-mail: colby.eisenbach@ttuhsc.edu

Received date: Jan 06, 2015, Accepted date: Jan 24, 2015, Publication date: Jan 27, 2015

Copyright: (c) 2015 Eisenbach C, et al. This is an open-access article distributed under the terms of the Creative Commons Attribution License, which permits unrestricted use, distribution, and reproduction in any medium, provided the original author and source are credited.

\begin{abstract}
Primary intraosseous haemangiomas represent benign endothelial neoplasms that are often discovered incidentally in approximately 10 to 12 percent of the general population. Although bony haemangiomas can be found in many regions of the appendicular and axial skeleton, most of which remain asymptomatic, those that arise in the vertebral column have the potential to elicit pain and cause neurological deficits in certain patients. In fact, a subset of primary vertebral intraosseous haemangiomas have been shown, albeit extremely rarely, to demonstrate aggressive, destructive and even malignant behavior. From a clinical and therapeutic standpoint, it is essential to recognize that such lesions possess certain radiological and nuclear imaging characteristics that, when observed in conjunction with patient decline, correlate strongly with the atypical and aggressive neoplasms. Ultimately, such lesions have the potential to give rise to an extremely uncommon, widespread, highly debilitating form of haemangiomatous pathology, hereafter termed "pseudomalignant haemangiomatosis". Fortunately, treatment in the form of directed radiotherapy has shown remarkable results in regards to symptomatic relief and complete neurologic restoration.
\end{abstract}

Keywords: Primary intraosseous hemangioma; Radiotherapy for hemangiomatosis; Radiation therapy; Hemangiomatosis of the spine; Vertebral hemangioma; Hemangiomatosis; Aggressive hemangioma of the spine

\section{Background}

First described by Virchow in 1867, primary intraosseous haemangiomas of the spine are characterized by the benign proliferation of the endothelial cells lining small blood vessels traversing the trabecular bony matrix within the vertebrae [1-3]. Developing most commonly in the 4th and 5th decades of life, such lesions are often discovered within the vertebral bodies, pedicles and spinous processes of the thoracic and lumbar spine [3-5]. However, contiguous extension and spread to the epidural space, lumbar vertebrae, cervical vertebrae, femur, sternum, skull, and orbit have also been documented in the literature [2-6]. By way of autopsy studies performed by Topfer and Junghanns in 1928 and 1932 respectively, the prevalence of such lesions within the general population is predicted to be anywhere from 10 to 12 percent with a female to male predominance of 9 to 2 . Although the vast majority of vertebral haemangiomas are asymptomatic and require no treatment, a subset of these haemangiomatous disorders possess certain characteristics that increase their likelihood of becoming symptomatic, destructive, and even quasimetastatic in nature [7-11]. Due to the rarity and unpredictability in the presentation and extent of these symptomatic spinal haemangiomatous disorders, it should come as no surprise that a wide array of treatment modalities have been developed to address such cases including: decompressive laminectomy, short segment posterior stabilization and fusion, intraarterial embolization, vertebroplasty, kyphoplasty, intralesional ethanol injection and radiotherapy [9,10,12-17]. Although no clear therapeutic protocol has been shown to be superior in the treatment of incidental, isolated vertebral haemangiomas, there is a prominent place for radiotherapy in the treatment of symptomatic or "atypical" haemangiomatous disease presentations [16-20]. Thus, in an effort to shed greater light on the role of radiation therapy in the management of such haemangiomatous variants and the multi-disciplinary approach that is often required for successful treatment and symptom management, we present a novel case of wide spread "pseudomalignant" spinal haemangiomatosis characterized by multi-level spinal cord compression, pathologic vertebral fractures, and appendicular skeletal invasion culminating in a remarkable symptomatic improvement as a result of radiotherapy administration.

\section{Case Report}

A 55-year-old Hispanic female presented with worsening lower back pain, which radiated into her lower extremities bilaterally in July 2011. The patient reported being treated for similar symptoms over the course of the previous year without relief from opioid or muscle relaxer use. Although the patient reported pain and discomfort related to muscle spasm, the patient had no neurologic deficits to suggest severe spinal cord compression at any level at this point in her disease course. However, upon review of previously obtained radiographic images by her PCP, initial assessment was concerning for metastatic lytic lesions of the spine with possible cord compression at T11-T12. Follow-up imaging at the time of admission revealed an L4 compression fracture with severe spinal canal stenosis at L4-L5. Multiple focal areas of intramedullary signal alteration were also observed throughout the thoracic vertebrae, lumbar vertebrae, sacrum, ilium and sternum. Such abnormalities are suspect for wide spread metastasis from an unknown primary source or a form of skeletal angiomatous disease. Subsequent CT guided needle core biopsy of the left iliac wing yielded insufficient tissue and blood despite three consecutive attempts. A repeat biopsy of the right sacrum revealed bone with intramedullary vasculature suggestive of capillary type 
hemangioma, essentially ruling out metastatic carcinoma of unknown origin. In an effort to insure an accurate diagnosis, samples were sent to Mayo Clinic and a confirmatory histopathology report of capillary type hemangioma was later received. Despite subsequent patient referral, problems encountered regarding patient insurance resulted in a periodic lapse in care.

In March 2012, our patient again presented to her local emergency department due to new onset, gradual loss of strength and paresthesias in her lower extremities bilaterally for which she now required the assistance of a walker to ambulate. Subsequent physical assessment revealed marked atrophy of her right lower extremity musculature with progressive weakness bilaterally. Considering the extent of disease and rapid neurologic decline, the patient was immediately referred for further imaging and a multi-disciplinary assessment to develop a plan of care. An MRI revealed significant disease progression with multiple enhancing lesions within the cervical spine, clivus, right calvarium, right clavicular head and right humeral head. Again, numerous enhancing lesions were visualized throughout the thoracic vertebrae, lumbar vertebrae and sacrum with extension into posterior elements i.e. pedicles, laminae and spinous processes. Significant compression fractures of T5 and T11 compounded by retropulsion of fragments into the spinal canal resulting in stenosis and cord compression was noted. Furthermore, complete destruction and collapse of L1 through L4 accompanied by compression of cauda equina nerve roots was reported. Open biopsy on the heavily involved L4 vertebral level was performed, followed by partial facetectomy, pediculectomy and corpectomy in an attempt to partially relieve compression and obtain another histologic sample. Histopathology of the specimen was again indicative of extensive intraosseous capillary type haemangioma. Following her recovery, the patient was informed that due to the height of her disease burden, surgery was not a possibility and she was discharged home.

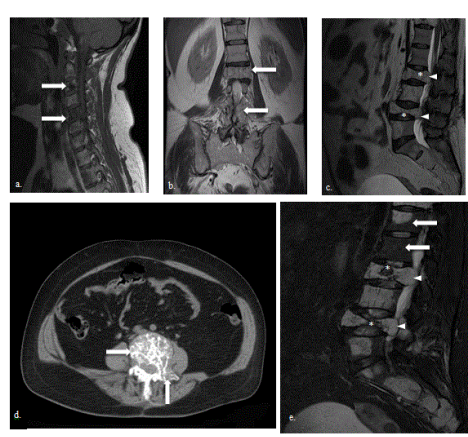

Figure 1: (a-e) Sagittal and coronal magnetic resonance images of cervical, thoracic and lumbar vertebral levels demonstrating widespread tumor invasion and osseous destruction.1d :represents a CT axial view demonstrating characteristic coarse bony trabeculations, complete vertebral body involvement with pedicular and transverse process invasion. Arrow heads represent areas of spinal cord compression. Arrows represent intraosseous vertebral involvement. Asterisks represent compression fractures.

Following several months of self-management and narcotic pain control, the patient presented with symptomatic progression of total motor paralysis and bilateral foot drop. Shortly thereafter, the patient was referred to Southwest Cancer Treatment and Research Center in
Lubbock, Texas for assessment by a multi-disciplinary team of neurosurgeons and radiation oncologists. A radiotherapy regimen was decided upon and the patient received $30 \mathrm{GY}$ in 15 fractions to her thoracic vertebrae extending from $\mathrm{T} 5$ to $\mathrm{T} 10$. The treatment took place from late May 2013 to mid-June 2013. Patient follow up in November 2013 revealed improvement in symptoms with the patient regaining the ability to ambulate with a walker and eliminating her need for narcotic pain medications. Six months post-radiotherapy, the patient continued to improve from a symptomatic standpoint, with marked improvement in her ability to ambulate requiring only intermittent assistance from a cane. After 1 year post-radiotherapy, the patient remains relatively asymptomatic with stable disease observed on MRI.

\section{Discussion}

Despite the relative commonality of vertebral haemangiomas, most being found incidentally on imaging performed for unrelated purposes, the vast majority of these benign endothelial hamartomatous lesions are asymptomatic [3-5,9,21]. However, as in the case of the patient presented above, significant discomfort and neurologic decline has been documented in the literature, albeit very rarely. Such symptoms include lower back pain, spasticity, weakness, bladder and fecal incontinence, and paralysis to name a few [7-11]. Certain criteria in the literature aid in the recognition of potential or frank neurologic deficits, many of which correlate directly to findings on radiographic and nuclear imaging as seen in Table 1 [6,21-24]. From a pathophysiologic standpoint, categorization of primary intraosseous haemangioma depends largely upon the vessel caliber and degree of trabecular bone formation present within the lesion. Large vessel formation and secondary dilation that prevents bony matrix intrusion or fatty stromal invasion is indicative of cavernous haemangiomas [21]. In contrast, small vessel endothelial proliferation that permits development of bony trabeculae and stromal tissue retention is descriptive of capillary-type haemangioma like that found in the above patient. There is no denying that the pathophysiologic process behind primary intraosseous haemangiomas can result in cortical weakening and pathologic fracture, as seen in this patient. This is likely due to a reactive bony sclerotic change that accompanies the abnormal vascular proliferation. In addition, erosion into the pedicles, laminae and spinous process harkens to a malignant process and is unusual in vertebral haemangioma pathology $[11,25,26]$. Single, noninvasive, and non-destructive lesions are considered the norm in regards to primary intraosseous haemangiomas. Thus, the undeniable presence of, pathologic fracture, total vertebral invasion and widespread involvement of the axial skeleton with extension into the limbs, skull and pelvic girdle, in this patient represents an enigmatic deviation from the norm. Ultimately, these facts altered the disease trajectory and influenced therapeutic decision-making. Indeed, to date, only a handful of individual cases in the literature describe similar findings [11,25-27]. Yet, none, to our knowledge, have demonstrated such extensive disease as that characterized by the multiple compression fractures and multi-level spinal cord compression points seen in this individual.

Since the first description of haemangiomas within the axial skeleton in 1867, a tremendous effort has been put forth to characterize and describe these lesions using radiographic and nuclear imaging techniques [1]. Radiographically, vertebral haemangiomas demonstrate a distinct pattern of prominent radiopaque trabeculae distributed in a lamellar pattern interspersed with radiolucent vasculature. Coined by Pernam in 1926, this characteristic "jailhouse" 
or "honey-comb" pattern along with any evidence of pathological fracture should garner a high degree of suspicion for primary intraosseous haemangioma when discovered on X-ray $[5,6,21,28]$. In addition to traditional radiography, computed tomography scans have emerged as a tremendously valuable imaging modality; providing physicians with vital information regarding extent, invasion and pathologic degenerative changes that may occur as a result of aberrant stromal and vasculitic proliferation. Similar to its more primitive cousin the traditional X-ray, transverse CT cross-sections of vertebral haemangiomas yield a characteristic "polka-dot" appearance representing the sclerotic columns of trabeculae surrounded by a large amount of fatty stroma and prominent vasculature $[6,21,29]$. An example of this phenomenon is evident in axial scan obtained from this patient seen in Figure 1d. Despite the contributory role that the above imaging techniques play in assessing osseous haemangiomas, MRI remains the gold standard diagnostic imaging modality for axial and appendicular skeletal haemangiomas revealing punctuate areas of increased signal intensity in a background of decreased signal intensity indicative, once again, of the sclerotic cancellous bone matrix within fatty stroma and pronounced vasculature as seen in Figure 1a-1c and $1 \mathrm{e}[21,26,28]$. All of the above findings are descriptive of simple benign intraosseous hemangiomas. Yet, the specifics of the presented case requires an in depth look at how the pseudomalignant, symptomatic, invasive, and destructive primary intraosseous haemangiomas subtypes differ from their asymptomatic, incidental counterparts upon obtaining nuclear imaging. Fortunately, several anatomic features, if observed on CT or MRI, have been found to be highly correlated with aggressiveness, development of spinal cord compression, and severe patient discomfort much like that observed in case presented above. Likewise, certain absorbance patterns when obtained on nuclear imaging are correlated with an increase in invasiveness [6,21,22,24,28]. For simplicity and clarity this information has been provided in the following table:

\begin{tabular}{|c|c|}
\hline \multicolumn{2}{|c|}{$\begin{array}{l}\text { Indicators for the Development/Presence of Symptomatic or Invasive Vertebral Haemangioma: } \\
\text { Nuclear Imaging and Anatomic Markers in Tumor Structure }\end{array}$} \\
\hline Low signal intensity on T-1 weighted Magnetic Resonance Imaging & Evidence of expansion of haemangioma into the epidural space \\
\hline Irregular "honey-comb" pattern on X-ray & Extension into posterior elements i.e. pedicles, lamina, neural arch \\
\hline Complete vertebral body involvement & Variable post-contrast enhancement on $\mathrm{CT}$ or $\mathrm{MRI}$ \\
\hline Hypodense mass with soft tissue invasion & Cortical expansion and pathologic fracture \\
\hline
\end{tabular}

Table 1: Pertinent imaging characteristics often observed in atypical and aggressive primary intraosseous haemangiomas.

Even though certain reliable symptomatic predictors exist, the incidence of any symptom development in individuals with vertebral haemangiomas is an extremely rare occurrence. However, in the case of the above patient this usually benign tumor exhibited many of the properties shown in Table 1 and has become one of only a few documented cases of vertebral haemangiomatous disease in the literature to demonstrate malignant characteristics from both a nuclear imaging and symptomatic standpoint [7-11,25,28]. This particular case demonstrates extremely rare and novel aspects of primary intraosseous vertebral haemangiomas representing a distinct subset of pathology that we have termed "pseudomalignant haemangiomatosis". Considering the resemblance of this aggressive, yet benign, primary intramedullary neoplastic subtype to lytic lesions from a distant metastatic source it is essential to recognize the "telltale" signs of a haemangiomatous process. Namely, the "jailhouse" or "honeycomb" appearance on X-ray, the near pathognomonic "polka dot" pattern on CT and the high signal intensity alteration on MRI $[6,21,22,24,28]$. Such observations, when combined with clinical and histologic evidence should aid in the successful recognition of a statistical outlier like pseudomalignant haemangiomatosis.

Although it is well documented that a large majority of vertebral haemangiomas require no treatment intervention. A clinical guideline for the successful treatment of highly aggressive or symptomatic vertebral haemangiomas has yet to be developed. Although no consensus has been reached to justify one treatment modality over another, it is important to keep in mind that disease presentation, symptom management and rapidity of neurologic decline are essential aspects to consider when deciding upon the therapeutic course of action. For severe or recalcitrant pain or gradual neurologic decline, radiotherapy has stood the test of time with multiple retrospective and prospective studies demonstrating tremendous pain reduction, partial to complete neurological deficit reversal, and decrease in overall disease burden the details of which are graphically represented in Table 2 [16,29-35]. With regards to this particular patient, this information only serves to validate an already proven outcome.

\section{Symptomatic Relief and Neurologic Recovery Obtained from Radiotherapy Administration in the Treatment of Vertebral Haemangioma}

\begin{tabular}{|l|l|l|l|l|l|l|}
\hline Primary Investigators & $\begin{array}{l}\text { Number of } \\
\text { Patients }\end{array}$ & $\begin{array}{l}\text { Average Follow -Up } \\
\text { Time }\end{array}$ & $\begin{array}{l}\text { Average Radiation } \\
\text { Dosage }\end{array}$ & $\begin{array}{l}\text { Complete Pain Relief/ } \\
\text { Full Neurologic } \\
\text { Recovery }\end{array}$ & $\begin{array}{l}\text { Partial Pain Relief/ } \\
\text { Partial } \\
\text { Recovery }\end{array}$ & $\begin{array}{l}\text { Nourologic Pain Relief/No } \\
\text { Neurologic Recovery }\end{array}$ \\
\hline Miszczyk and Ficek [30] & 14 & 6 months & $20-30 \mathrm{~Gy}$ & $67 \%$ & $33 \%$ & $0 \%$ \\
\hline Heyd [32] & 84 & 68 months & $34 \mathrm{~Gy}$ & $61.9 \%$ & $28.6 \%$ & $9.5 \%$ \\
\hline $\begin{array}{l}\text { Suparna and Vadhiraja } \\
\text { [29] }\end{array}$ & 6 & 4.5 months & $8-30 \mathrm{~Gy}$ & & $66.7 \%$ & $33.3 \%$ \\
\hline
\end{tabular}




\begin{tabular}{|c|c|c|c|c|c|c|}
\hline Yang and Zang [28] & 23 & 2.5 months & 30-40 Gy & $80 \%$ & & \\
\hline Asthana and Tandon [34] & 17 & 1 month & $35-40 \mathrm{~Gy}$ & $76.4 \%$ & $11.8 \%$ & $11.8 \%$ \\
\hline Aich and Deb [31] & 7 & 6 months & $40 \mathrm{~Gy}$ & $100 \%$ & $0 \%$ & $0 \%$ \\
\hline Templin et al. [17] & 117 & & $36-40$ Gy & $82 \%$ & & \\
\hline Micke and Rades & 82 & 70 months & $34 \mathrm{~Gy}$ & $61 \%$ & $29.2 \%$ & $9.8 \%$ \\
\hline Faria [35] & 9 & 8-44 months & $30-40 \mathrm{~Gy}$ & $88.9 \%$ & & $11.1 \%$ \\
\hline $\begin{array}{l}\text { Miszczk and Tukiendorf } \\
\text { [30] }\end{array}$ & 101 & 18 months & 8-30 Gy & $64 \%$ & $22 \%$ & $14 \%$ \\
\hline
\end{tabular}

Table 2: Multiple prospective and retrospective studies demonstrating the success of radiotherapy in the treatment of symptomatic vertebral haemangiomas.

\section{Conclusion}

In spite of the well documented, benign nature of this common vascular abnormality, the variable presentation, atypical distribution and extent of disease progression in this case represents a marked detour regarding the so-called "normal" course of this tumor type. The involvement of cervical, thoracic, lumbar, and sacral spinal segments coupled with spread into the skull, right humerus and clavicle was concerning for metastatic disease. Likewise, the invasion of posterior vertebral elements resulting in total collapse, fragment retropulsion, spinal canal stenosis and direct cord compression yielding significant pain and lower extremity weakness again fostered a probable metastatic etiology. Despite the presence of some "typical" nuclear imaging findings, like that of the "polka dot" pattern on axial CT, representing the coarse bony trabeculation amongst a background of hypervascularity, the overwhelming aggressive characteristics observed in this case may have played a role in delaying the ultimate diagnosis. Overall, this case demonstrates the difficulty in differentiating between the pseudomalignant variant of primary intraosseous haemangiomas and a number of truly malignant bony neoplasms. In the midst of such a rare and problematic diagnostic dilemma, there is no denying that the therapeutic choice in this case brought about a complete symptomatic turn around for the patient. This case solidifies the essential role that directed, appropriately dosed, radiotherapy plays in the treatment of even the most aggressive cases of primary intraosseous vertebral haemangiomas.

\section{References}

1. Virchow R (1867) Die krankhaften Geschwulste. Berlin: Hirschwald 3: 306-496.

2. Topfer D (1928) Über ein infiltrierend wachsendes hamangiom der haut und multiple kapillarektasien der haut und inneren organe II zur kenntnis der wirbelangiome. Frankfurth Zeits Path 36: 33.

3. Junghanns H (1932) Hamangiom des Brucstwirbelkorpers mit Ruckenmark-kompression. Laminektomie: Heilung. Arch Klin Chir 169: 321-330.

4. Ghormley RK, Adson AW (1941) Hemangioma of vertebrae. J Bone Joint Surg Am 23: 887-895.

5. Perman E. On haemangiomata in the spinal column. Acta Chir Scand 1926;61:91-105

6. Laredo JD, Reizine D, Bard M, Merland JJ (1986) Vertebral hemangiomas: radiologic evaluation. Radiology 161: 183-189.
7. Ahn H, Jhaveri S, Yee A, Finkelstein J (2005) Lumbar vertebral hemangioma causing cauda equina syndrome: a case report. Spine (Phila Pa 1976) 30: E662-664.

8. Aksu G, Fayda M, Saynak M, Karadeniz A (2008) Spinal Cord Compression Due to Vertebral Hemangioma. Orthopedics 31: 169.

9. Fox MW, Onofrio BM (1993) The natural history and management of symptomatic and asymptomatic vertebral hemangiomas. J Neurosurg 78: 36-45.

10. Doppman JL, Oldfield EH, Heiss JD (2000) Symptomatic Vertebral Hemangiomas: Treatment by Means of Direct Intralesional Injection of Ethanol. Vascular and Interventional Radiology 214: 341-348.

11. Jones JO, Bruel BM, Vattam SR (2009) Management of painful vertebral hemangiomas with kyphoplasty: a report of two cases and a literature review. Pain Physician 12: E297-303.

12. Acosta FL Jr, Sanai N, Chi JH, Dowd CF, Chin C, et al. (2008) Comprehensive management of symptomatic and aggressive vertebral hemangiomas. Neurosurg Clin N Am 19: 17-29.

13. Acosta FL Jr, Dowd CF, Chin C, Tihan T, Ames CP, et al. (2006) Current treatment strategies and outcomes in the management of symptomatic vertebral hemangiomas. Neurosurgery 58: 287-295.

14. Bandiera S, Gasbarrini A, De Iure F, Cappuccio M, Picci P, et al. (2002) Symptomatic vertebral hemangioma: the treatment of 23 cases and a review of the literature. Chir Organi Mov 87: 1-15.

15. Zito G, Kadis GN (1980) Multiple vertebral hemangiomas resembling metastases with spinal cord compression. Arch Neurol 37: 247-248.

16. Schrock WB, Wetzel RJ, Tanner SC, Khan MA (2011) Aggressive hemangioma of the thoracic spine. J Radiol Case Rep 5: 7-13.

17. Templin CR, Stambough JB, Stambough JL (2004) Acute spinal cord compression caused by vertebral hemangioma. Spine J 4: 595-600.

18. Asthana AK, Tandon SC, Pant GC, Srivastava A, Pradhan S (1990) Radiation therapy for symptomatic vertebral haemangioma. Clin Oncol (R Coll Radiol) 2: 159-162.

19. Rades D, Bajrovic A, Alberti W, Rudat V Clinical investigation: benign disease Is there a dose-effect relationship for the treatment of symptomatic vertebral hemangioma? International Journal of Radiation Oncology ${ }^{\star}$ Biology ${ }^{\star}$ Physics.

20. Ropper AE, Cahill KS, Hanna JW, McCarthy EF, Gokaslan ZL, et al. (2011) Primary vertebral tumors: a review of epidemiologic, histological, and imaging findings, Part I: benign tumors. Neurosurgery 69: 1171-1180.

21. Cross JJ, Antoun NM, Laing RJ, Xuereb J (2000) Imaging of compressive vertebral haemangiomas. Eur Radiol 10: 997-1002.

22. Friedman DP (1996) Symptomatic vertebral hemangiomas: MR findings. AJR Am J Roentgenol 167: 359-364.

23. Puvaneswary M, Cuganesan R, Barbarawi M, Spittaler P (2003) Vertebral haemangioma causing cord compression: MRI findings. Australas Radiol 47: 190-193. 
Citation: Eisenbach C, Hansen C, Torres C (2015) The Role of Radiotherapy in the Treatment and Diagnosis of Pseudomalignant Vertebral Haemangiomatosis: A Case Report. J Nucl Med Radiat Ther 6: 209. doi:10.4172/2155-9619.1000209

Page 5 of 5

24. Kumar K, Nguyen R, Bishop S (2010) "A comparative analysis of the results of vertebroplasty and kyphoplasty in osteoporotic vertebral compression fractures." Neurosurgery 67: 171-188.

25. Askenasy H, Behmoaram A (1957) Neurological manifestations in haemangioma of the vertebrae. J Neurol Neurosurg Psychiatry 20: 276-284.

26. Vinay S, Khan SK, Braybrooke JR (2011) Lumbar vertebral haemangioma causing pathological fracture, epidural haemorrhage, and cord compression: a case report and review of literature. J Spinal Cord Med 34: 335-339.

27. Friedman DP (1996) Symptomatic vertebral hemangiomas: MR findings. AJR Am J Roentgenol 167: 359-364.

28. Yang ZY, Zhang LJ, Chen ZX, Hu HY (1985) Hemangioma of the vertebral column. A report on twenty-three patients with special reference to functional recovery after radiation therapy. Acta Radiol Oncol 24: 129-132.

29. Suparna HC, Vadhiraja BM, Apsani RC, Seetharamaiah T, Fernandes DJ, et al. (2006) Symptomatic vertebral hemangiomas- results of treatment with radiotherapy. Indian J Radiol Imaging 16: 37-40.
30. Miszczyk L, Tukiendorf A (2012) Radiotherapy of painful vertebral hemangiomas: the single center retrospective analysis of 137 cases. Int J Radiat Oncol Biol Phys 82: e173-180.

31. Aich RK, Deb AR, Banerjee A, Karim R, Gupta P (2010) Symptomatic vertebral hemangioma: treatment with radiotherapy. below J Cancer Res Ther 6: 199-203.

32. Heyd R, Seegenschmiedt MH, Rades D, Winkler C, Eich HT , et al. (2010) "Radiotherapy for symptomatic vertebral hemangiomas: results of a multicenter study and literature review." International Journal of Radiation Oncology ${ }^{\star}$ Biology* Physics 77.1: 217-225.

33. Schrock WB, Wetzel RJ, Tanner SC, Khan MA (2011) Aggressive hemangioma of the thoracic spine. J Radiol Case Rep 5: 7-13.

34. Asthana AK, Tandon SC, Pant GC, Srivastava A, Pradhan S (1990) Radiation therapy for symptomatic vertebral haemangioma. Clin Oncol (R Coll Radiol) 2: 159-162.

35. Faria SL, Schlupp WR, Chiminazzo H Jr (1985) Radiotherapy in the treatment of vertebral hemangiomas. Int J Radiat Oncol Biol Phys 11: 387-390. 